\title{
The First Generation of Chemoprevention Studies - an Initial Step in the Right Direction
}

\author{
Stefan Paepke Marion Kiechle \\ Interdisziplinäres Brustzentrum, Frauenklinik rechts der Isar, Technische Universität München, Germany
}

\section{From the Initial Idea to the First Study Results}

Inspired by the positive results of early breast cancer therapy studies, 20 years ago the idea of adopting the least harmful of the existing arsenal of endocrine therapies as prophylatic agents was implemented. Included were healthy women with the then known risk variables such as age, family history and pre-invasive lesions.

Only a quarter of all women with an increased risk of breast cancer has a realistic assessment of their individual risk of disease $[1,2]$. This reflects both the perceived threat of the disease as well as the wish to protect themselves. Only 19.5\% of women in the high-risk group are informed about the possibilities of chemoprevention while $55.3 \%$ stated they would be prepared to use it if available [3, 4].

Lifestyle changes, such as improved nutrition and physical activity as well as surgery and chemoprevention are measures currently available to these women to decrease their breast cancer risk. The rationale for using anti-estrogens such as tamoxifen for the prevention of breast cancer is provided by the demonstrated risk reduction of $43-49 \%$ in the incidence of ipsi- or contra-lateral invasive recurrences in comparison to placebo in women with DCIS or early stage breast cancer [5]. This has been confirmed by placebo-controlled studies of breast cancer prevention with tamoxifen. The most extensive study worldwide, the National Surgical Adjuvant Breast and Bowel Project P-1 with 13388 participants, showed a reduction in the incidence of receptor-positive invasive and non-invasive breast cancers of about $50 \%$ in all age groups.

Based on these data, the Food and Drug Administration approved tamoxifen prophylaxis for women with a 5 year risk of disease $>1.66 \%$, marking the historic first FDA approval of any agent for cancer risk reduction. The P-1 trial and FDA approval have created a paradigm shift toward pharmacologic preventive approaches for controlling breast cancer [6]. Thus the first step has been taken and confirmed that tamoxifen reduces the short-term risk to developing breast cancer. Those that most benefit are the perimenopausal and hysterectomized women with low risk of thrombosis [7]. The greatest risk reduction, corresponding to a GAIL calculated risk of $>5 \%$, emerges in the group with CLIS (carcinoma lobulare in situ) or those women under 50 with more than one first-degree relative suffering from breast cancer. In this subgroup, the health economic cost and benefit analysis is also positive [8]. The most extensive European prevention study (International Breast Cancer Intervention Study I = IBIS I) demonstrated a reduction of breast cancer incidence in women with a median age of 51 years $(33 \%$, odds ratio $0.67 ; 95 \% \mathrm{CI}$ $0.49-0.91)$. Hormone replacement therapy taken concomitantly in $40 \%$ of the participating women did not impede the preventive tamoxifen effect. A meta analysis of all 4 randomized tamoxifen prevention studies illustrates a reduction in the incidence of breast cancer of $38 \%[9,10]$. However, it must be stated that $44 \%$ of women attending a prevention consulation, do refuse tamoxifen as a preventive agent due to concerns about potential side effects [11].

Having proved in principle the possibility of breast cancer prevention, more substances have been and will be investigated in the field with the aim of a reduction in incidence and mortality with increased therapeutical index.

\section{Selective Receptor Modulators (SERM) - Raloxifen}

Secondary observations of the MORE study (Multiple Outcomes of Raloxifen Evaluation - raloxifen versus placebo in order to prevent fractures caused by osteoporosis) demonstrated a significant reduction (RR 0.28) of estrogen receptor positive breast cancers in the raloxifen arm [12]. In contrast to the results of the NSABP-P1 study in which a $33 \%$ reduction

\begin{tabular}{ll}
\hline KARGER & @ 2006 S. Karger GmbH, Freiburg \\
Fax +497614520714 & Accessible online at: \\
$\begin{array}{l}\text { E-mail Information@Karger.de } \\
\text { www.karger.com }\end{array}$ & www.karger.com/brc
\end{tabular}

Dr. Stefan Paepke

Diagnostische und Operative Senologie

Frauenklinik rechts der Isar

Technische Universität München

Ismaninger Str. 22, 81675 München, Germany

Tel. +49 89 4140-5433, Fax -4811, E-mail stefan.paepke@lrz.tum.de 
of breast cancer was achieved by tamoxifen in the first year with a stable risk reduction throughout the whole term of the study, the preventive effect of raloxifen was first registered after 1 year of treatment.

A sub-group analysis showed a significantly higher risk of breast cancer in the placebo group correlating with higher serum estradiol levels and a more distinct risk reduction under raloxifen in this population [8]. Recent results of the MORE/CORE study [13] proved the preventive effectiveness of raloxifen for the subgroup of the osteoporotic postmenopausal women, whereby only about $50 \%$ of the participants in the study would have been expected to have an increased risk of breast cancer [14]. As a result of the implied preventive effect of $72 \%$ after a 4 -year raloxifen treatment, an enlarged trial of altogether 8 years of raloxifen versus 4 years of raloxifen and 4 years of placebo was initiated. Results reported a $66 \%$ reduction in breast cancer incidence of all invasive (HR 0.34; CI 0.22-0.50) and 76\% of receptor-positive breast cancers (HR 0.24; CI 0.15-0.40). An important additional finding was that raloxifen led to a reduction in mammographic density, with corresponding improvement in early detection of the cancers in the raloxifen arm.

The STAR study compared the standard tamoxifen with raloxifen in a trial with 22,000 women. First results were presented in 2006 showing an identical risk reduction of invasive breast cancers in both arms, but a less distinct preventive effect in the non-invasive breast cancer subgroup. Raloxifen presented a rather better side effect profile than tamoxifen.

\section{Aromatase Inhibitors - Anastrozole}

Aromatase inhibitors (AIs) suppress serum estradiol levels below detection levels in postmenopausal women. This as well their proven efficacy and positive tolerability profile compared to tamoxifen has led to automatic consideration of the AIs as preventive agents. These considerations are supported by the ATAC study which reports a reduction in contra-lateral recurrence rates of $58 \%[9,15]$. The improved therapeutical index for anastrozole leads to the expectation of a $77 \%$ reduction in breast cancer incidence. The IBIS II trial is currently recruiting 6000 postmenopausal women at increased risk for developing breast cancer $(\mathrm{RR}>2)$ and compares anastrozole versus placebo.

\section{Conclusions}

The promising results of the present breast cancer prevention studies suggest that a reduction in the incidence of re- ceptor-positive breast cancers is possible by preventing carcinogenesis in some form rather than blocking tumor progression once diagnosis has been confirmed. Although preliminary, this opens a new dimension in the treatment of breast cancer, which warrants further exploration. The problem of treating a huge number of healthy women in order to prevent disease in a small subgroup of these women remains. Improvements in risk calculation models support physicians advising high-risk women, but a more targeted selection of those likely to develop breast cancer, for example via genetic profiling, is required.

The positive impact of breast cancer prevention on overall survival has yet to be proved. Despite good intentions an individual risk-benefit balance has to be ensured. Thus chemo- as well as operative prevention measures should only be conducted under conditions of a study and in established centers. New substance classes should be considered in the future in the quest for effective preventive agents independent of tumor characteristics such as the hormone receptor-status. Further agents under consideration are those which inhibit known mechanistic pathways of carcinogenesis such as the anti-proliferative, anti-angiogenetic and apoptosis-inducing agents cyclooxygenase, lipoxygenase and cyclin-dependent kinase inhibitors [6, 16-18]. Future studies results will shed light on which substances can be used most effectively with the least side effects, define the most appropriate populations and the length of treatment necessary.

The first generation of prevention studies has included women with a defined group risk and has been limited to the endocrine agents - the anti-estrogens, selective receptor modulators and aromatase inhibitors. The most mature results suggest that cost-effectiveness is proven for tamoxifen in patients a high risk of breast cancer (3-5\%) [19]. At present raloxifen appears to be the substance with the best therapeutical index. We are anxiously awaiting the results of the IBIS II study with anastrozole.

For a woman with an increased risk of breast cancer seeking advice on prevention today, it can be stated that tamoxifen has the greatest preventive benefit for the younger hysterectomized woman, whereas women with higher estrogen levels and low bone density benefit most of all from raloxifen. Women should be offered participation in the IBIS II study providing the chance of prevention with anastrozole. Further and future evaluations of prevention studies will reveal the influence of preventive measures on breast cancer specific mortality and on overall mortality. The benefit must ultimately be balanced against the harm, principally of side effects but also the currently high number of women undergoing unnecessary prevention. 


\section{References}

1 Neise C, Rauchfuss M, Paepke S, Baier K, Lichtenegger W: Risk perception and psychological strain in women with a family history of breast cancer. Onkologie 2001;24:470-475.

2 Heisey RE, Pimlott N, Dummond NA, Clemons MJ, Cummings S: Women's view on chemoprevention of breast cancer: a qualitative study. Breast Canc Res Treatm 2004;88:160.

3 Paepke S, Schubert R, Hüttner Ch, Blohmer JU, Lichtenegger W: Position on prevention of breast cancer - an investigation of 2100 women. EJC 2002;38 (Suppl 1):21-47.

4 Paepke S, v Minckwitz G, Kaufmann M, Raab G, Heinrich G, Schmutzler R; Torode J, Maier P, Jacobs VR, Kiechle M: Attitude towards the prevention of breast cancer - results of a survey of women with an average risk of breast cancer $(\mathrm{n}=7000)$ and free practising gynaecologists $(\mathrm{n}=800)$ in Germany. Eur J Cancer 2004;2:184.

5 Fisher B, Dignam J, Wolmark N, et al: Tamoxifen in treatment of intraductal breast cancer: National Surgical Adjuvant breast and bowel project B-24 randomized controlled trial. Lancet 1999;353: 1993-2000.

6 Fisher B, Costantino JP, Wickerham DL, et al: Tamoxifen für prevention of breast cancer: report of the National Surgical Adjuvant Breast and Bowel Project P1-study. J Natl Cancer Inst 1998;90: 1371-88.
7 Vogel VG, Costantino JP, Wickerham DL, et al: National Surgical Adjuvant Breast and Bowel Project: prevention trials and endocrine therapy of ductal carcinoma in situ. Clin Canc Res 2003;9: 495-501.

8 Chlebowski RT, Nananda C, Winer EP: American Society of clinical oncology technology assessment of pharmacologic interventions for breast cancer risk reduction including tamoxifen, raloxifene and aromatase inhibition. J Clin Oncol 2002;20: 3328-3343.

9 Cuzick J: Update on new studies in Europe. Eur J Cancer 2002;38:abstr 20.

10 Veronesi U, Maisonneuve P, Sacchini V, et al: Tamoxifen for breast cancer among hysterectomised women. Lancet 2002;359:1122-1124.

11 Bober SL, Hoke LA, Duda RBD, Regan MM, Tung NM: Decision-making about tamoxifen in women at high risk for breast cancer: clinical and psychological factors. J Clin Oncol 2004;22: 4951-4957.

12 Cummings SR, Eckert S, Krueger KA, et al: The effect of raloxifene on risk of breast cancer in postmenopausal women: results from the MORE randomized trial. Multiple outcomes of Raloxife evaluation. JAMA 1999;281:2189-2197.
3 Martino S, Cauley JA, Barrett-Conor E, et al: Continuing outcomes relevant to Evista: Breast cance incidence in postmenopausal osteoporotic women in a randomized trial of raloxifene. JNCI 2004;96 1751-1761.

14 Kalidas M, Hilsenbeck S, Brown P: Defining the role of Raloxifene for the prevention of breast cancer. JNCI 2004;96:1731-32.

15 Baum $\mathrm{M}$ on behalf of the ATAC Trialist Group The ATAC (Arimidex, Tamoxifen alone or in Combination) adjuvant breast cancer trial in postmenopausal women. Breast Can Res Treat 2001;2 abstr 8 .

16 Arun B, Lammey J, Broglio K, Valero V, Babiera G, Browne D, Hortobagyi GN, Sneige N : Downregulation of estrogen receptor expression with celecoxib in breast tissue of women at increased risk for developing breast cancer. Breast Canc Res Treatm 2004;88:157.

17 Clifford JL, Menter DG, Wang M, et al: Retinoid receptor dependent and -independent effects of $\mathrm{N}$-(4-hydroxyphenyl)retinamide in $\mathrm{F} 9$ embryonal carcinoma cells. Cancer Res 1999;59:14-18.

18 Veronesi U, De Palo G, Marubini E, et al: A randomized trial of fenretinide to prevent second breast malignancy in women with early breast cancer. J Natl Cancer Inst 1999;91:1847-1856.

19 Melnikow J, Kuenneth C, Helms LJ, et al: Chemoprevention: drug pricing and mortality. Cancer 2006;107:950-8. 